\title{
Contribution of the cyto-histopathological diagnosis and ultrastructural parameters to the evaluation of maxillary cysts - a 10-year multidisciplinary approach
}

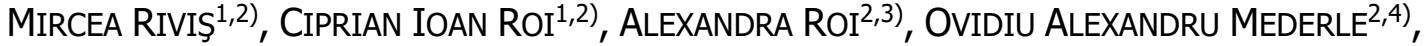 \\ DiANA FlORINA NiCA ${ }^{1)}$, DOINA CHIORAN ${ }^{1}$, LAURA CRISTINA RUSU ${ }^{2,3)}$, STELA IURCIUC ${ }^{2,5}$, \\ ADINA VĂLEANU ${ }^{1)}$ \\ 1) Department of Anesthesiology and Oral Surgery, Faculty of Dental Medicine, Victor Babeş University of Medicine and \\ Pharmacy, Timişoara, Romania \\ 2) Multidisciplinary Center for Research, Evaluation, Diagnosis and Therapies in Oral Medicine, Victor Babeş University of \\ Medicine and Pharmacy, Timişoara, Romania \\ ${ }^{3)}$ Department of Oral Pathology, Faculty of Dental Medicine, Victor Babeş University of Medicine and Pharmacy, Timişoara, \\ Romania \\ 4) Department of Surgery, Faculty of Medicine, Victor Babeş University of Medicine and Pharmacy, Timişoara, Romania \\ 5) Discipline of Ambulatory Internal Medicine, Cardiovascular Prevention and Rehabilitation, Department of Cardiology, \\ Faculty of Medicine, Victor Babeş University of Medicine and Pharmacy, Timişoara, Romania
}

\begin{abstract}
Diagnostic and treatment plans in cystic jawbone tumors are often difficult to address. The etiopathogenic links involved in cell-matrix differentiation disorders are complex. Quantification of the inflammatory process in the evolution of cystic odontogenic lesions highlights a particular reactivity of the host, especially age-dependent and the endodontic-periodontal space interrelation, drawing attention to the difficulties of etiopathogenic, evolution, prognostic and treatment of these lesions. Difficulties in histopathological (HP) diagnosis are reported by the lack of morphofunctional integration of dental tissues, both topographically and evolutionarily, especially when odontogenic epithelial remains in the cystic wall, reactive bone condition, appearance and condition of the reactive epithelium are overlooked. In this study, we developed an interdisciplinary approach for the dynamics of tissue morphology found in the walls of maxillary cysts. Failure to recognize the tissues that form the cystic lesion leads to misinterpretations of pathology and to the wrong classification in the group of maxillary cysts. We analyzed by different techniques 564 biopsy fragments from maxillary cystic lesions, most of which are clinically classified as inflammatory or odontogenic ones. From our experience, we reevaluated the lesions with cystic changes and completed the diagnosis in 10-12\% of cases. The most common maxillary cystic lesion encountered by us was the root cyst, an inflammatory dental cyst, which has been over diagnosed clinically, radiologically and histopathologically. Recognition and selection of embryonic remnants from odontogenesis is crucial for the HP diagnosis of maxillary cysts, allowing the clinician to monitor treatment or to develop evolutionary-prognostic perspectives of odontogenic cystic lesions.
\end{abstract}

Keywords: cyto-histopathological diagnosis, cysts tumors, interdisciplinary approach.

\section{ㅁ Introduction}

The increased incidence of cysts in the maxillary and mandibular bones is clarified by the existence of ectomesenchymal and ectodermal derivatives from odontogenesis in the osseous connective tissue mass $[1,2]$. The presence of epithelial remnants from the enamel organ, from the fragmentation of dental lamina, from Hertwig's epithelial root sheath (epithelial rests of Malassez) and from the surface epithelium of maxillary embryonic processes, represents the starting point for forming odontogenic and nonodontogenic cysts [1,2].

Nonodontogenic epithelium is found only in the maxillary bone and represents the rest of the epithelium that covered the embryonic processes from which maxillary bones are developed. These tissue remnants are found along the suture lines of embryonic maxillary processes [3].

Another source of the nonodontogenic epithelium in the maxillary bone is represented by the vestiges of the nasopalatine duct of oronasal communication in fetal life. Embryonic remnants can be found in the incisive papilla zone. These are pseudo-cysts, because they are not lined by the epithelium $[4,5]$.

From odontogenic cysts, more than a half are radicular cysts developed from Malassez rests activated in the periodontal ligament due to inflammation after the destruction of the dental pulp tissue $[2,6]$.

This study has focused on the use of all possibilities of morphological and clinical diagnosis that find etiopathogenic links involved in the development and maintenance of maxillary cyst lesions, correlating cytological aspects with those histopathological (HP), histochemical, immunohistochemical (IHC) and electron microscopic in maxillary cysts with diverse clinical and radiological aspects. This type of cyst is not difficult to diagnose

This is an open-access article distributed under the terms of a Creative Commons Attribution-NonCommercial-ShareAlike 4.0 International Public License, which permits unrestricted use, adaptation, distribution and reproduction in any medium, non-commercially, provided the new creations are licensed under identical terms as the original work and the original work is properly cited. 
clinically and radiologically. These cysts consist of superior tissular differentiation, in which the inductive ecto-mesenchymal aspect determines the HP subtype and the preoperative and postoperative evolution of the lesions as well. The current study finds and observe the main morphological markers used for appreciating postoperative recurrence risk of the maxillary cysts.

\section{ㅁ Materials and Methods}

We studied 564 patients who underwent biopsy, presenting maxillary and mandibular cysts, clinically, radiologically and histopathologically examined between 2009 and 2019. The parameters which were examined (age, gender, initial symptomatology, anatomical localization, degree of affectation of the neighboring anatomical structures, radiological dimension, postoperative evolution) were referred to the HP type of cyst. Following techniques were applied:

\section{Histopathology}

The samples were placed in hermetically sealed, sterile containers, in a $4 \%$ formalin solution, after which they were stored in the refrigerator at a constant temperature of $4^{\circ} \mathrm{C}$. The samples were processed according to the paraffin inclusion technique. We performed the sections of the paraffin block, the deparaffinization, rehydration (or antigenic demasking in the case of immunohistochemistry technique) and the staining of smears.

The deparaffinization protocol involved carrying out three successive benzene baths, five minutes each, followed by two successive $100 \%$ ethanol baths, one $95 \%$ ethanol bath and one $70 \%$ ethanol bath, two minutes each.

The rehydration was performed by rinsing the samples with distilled water in two successive baths. HematoxylinEosin (HE) classical staining protocol was used for the HP examination. Staining, regardless of the chosen technique, was followed by dehydration in three ethanol baths in increasing concentrations and by clarification in three benzene baths.

\section{The cytological smears}

The cytological smears were obtained after a fineneedle $(22 \mathrm{G})$ aspiration (FNA) $(n=120)$, after minimally local anesthesia. If the bone wall was thick, a foramen was made in advance with the milling machine. The smears were examined using Papanicolaou (Pap) staining and APT (polychrome tannin blue)-Drăgan original method. The smears were graded based on cellularity (grade I, II, III), the dimension of the cell groups, cellular arrangement, nuclear structure alteration, the presence of nucleoli.

\section{Immunohistochemistry}

The specimens were fixed in $10 \%$ neutral buffered formalin for 48 hours and embedded in paraffin. The paraffin-embedded tissues were cut into $5 \mu \mathrm{m}$ sections. All the samples were stained using the HE classical protocol. We performed an enzyme pretreatment (Bond Enzyme Pretreatment Kit, Leica Biosystems, Newcastle upon Tyne, UK) for 10 minutes. Endogenous peroxidase blocking was done with $3 \%$ hydrogen peroxide for five minutes. This step was followed by incubation for 15 minutes with cluster of differentiation (CD) 20, cytokeratin
(CK) (monoclonal mouse anti-human CK, clone AE1/AE3) and CD68 (Novocastra, Newcastle upon Tyne, UK, rabbit polyclonal antibodies, ready to use) as primary antibodies. We utilized a set of CD antigen-specific monoclonal antibodies to detect different cell types within the tissues. These included anti-CD20 (B-cells), anti-CD68 (macrophages) and Ki67 proliferative index.

The Bond Polymer Refine Detection System (Leica Biosystems, Newcastle upon Tyne, UK) was used for visualization. 3,3'-Diaminobenzidine (DAB) tetrahydrochloride was applied as chromogen, and we used Hematoxylin for counterstaining. The entire IHC procedure was developed with Leica Bond-Max (Leica Biosystems, Newcastle upon Tyne, UK) autostainer.

Image acquisition and analysis were performed using Nikon Eclipse E600 microscope and Lucia G software for microscopic image analysis.

\section{Transmission electron microscopy}

For the examination using transmission electron microscopy (TEM), the Lehner technique (1996) allowed the reinclusion of paraffin blocks $(n=15)$. Post-fixation was made in $1 \%$ osmium tetroxide in $0.1 \mathrm{M}$ phosphate buffer solution at $\mathrm{pH} 7.3$ for one hour. Dehydration was made in ethanol at different concentrations, then the sections were fixed in Epon and the blocks were cut at $0.5 \mu \mathrm{m}$ thick. The contrasting sections were made with lead citrate and uranyl acetate.

\section{口 Results}

Based on the modified World Health Organization (WHO) Classification, in this study, the main type was represented by inflammatory cysts, $77.1 \%$ of the cases. In the inflammatory cyst group, radicular cysts were represented by $67 \%$ of the total cases, and residual cysts $-12 \%$. The dentigerous cysts and the keratocysts were each identified in the same percentage of $9 \%$. The periodontal lateral, nasopalatine, paradental, eruption cysts and other cysts were found in a value less than $3 \%$.

We have observed three postoperative recurrence cases of radicular cysts, with clinical symptoms of infection, and nine cases of keratocyst recurrence, six without any symptoms, diagnosed after radiological exam and three cases with pain and clinical manifestations.

We present, in Table 1, morphological aspects of maxillary cyst lesions found in case studies in histology.

In most of the HP sections, lining epithelium is either incomplete or alternates as layering and cell differentiation, having aspects of reactive hyperplasia or degenerative. We noticed marked edema and aspects of exocytosis to cysts with abundant inflammatory reactions. To certain cysts, lining epithelium presents an exuberant growth, which might simulate a squamous odontogenic tumor. In some specimens histologically examined, we did not find any epithelial lining of the cyst. We found only a fibrosis wall, thickened by extensive hyalinization and abundant nonspecific chronic inflammatory infiltrate, or granuloma reaction of foreign body and suppurative micro-hotspots.

We considered that the formation of the developmental radicular cyst is an evolutive succession of apical granuloma. The transition of granuloma to the cyst is gradual and is based on growing proportions of epithelium and gradual development of a clearly defined lumen. 
Table 1 - Morphological aspects of the cysts $(n=564)$

\begin{tabular}{|c|c|c|c|c|c|}
\hline No. & Morphological aspect & Type of lesion & $\begin{array}{c}\text { Patient age } \\
\text { (average) } \\
\text { [years] }\end{array}$ & Identification & $\begin{array}{l}\text { Role in local } \\
\text { recurrence }\end{array}$ \\
\hline 1. & Proliferative lining epithelium & $\begin{array}{l}\text { Inflamed odontogenic cysts } \\
\text { (inflammatory and developmental } \\
\text { type) }\end{array}$ & 28 & Frequent & $\begin{array}{c}+/- \\
\begin{array}{c}\text { Usually surgically } \\
\text { removed }\end{array} \\
\end{array}$ \\
\hline \multirow[b]{2}{*}{2.} & Active remnants of odontogenic epithelium & Inflammatory odontogenic cysts & $<20$ & Rare & + \\
\hline & Active remnants of odontogenic epithelium & Developmental cysts & $10-20$ & Frequent & + \\
\hline 3. & Inflammatory polymorph infiltrate & $\begin{array}{l}\text { Inflamed odontogenic cysts } \\
\text { (inflammatory and developmental } \\
\text { type), inflamed neoplasms }\end{array}$ & 34 & Frequent & $+/-$ \\
\hline 4. & Foamy macrophages & $\begin{array}{l}\text { Inflamed radicular cyst, inflamed } \\
\text { dentigerous cyst, hystiocytoid } \\
\text { lesions }\end{array}$ & 31 & Rarely & No \\
\hline 5. & Giant cells foreign body type & $\begin{array}{l}\text { Inflammatory odontogenic } \\
\text { cysts }\end{array}$ & 42 & Frequent & No \\
\hline & Giant cells foreign body type & $\begin{array}{l}\text { Developmental odontogenic } \\
\text { cysts }\end{array}$ & 35 & Rarely & No \\
\hline \multirow[t]{2}{*}{7.} & Cholesterol crystals & $\begin{array}{l}\text { Inflammatory odontogenic } \\
\text { cysts }\end{array}$ & 45 & Frequent & No \\
\hline & Cholesterol crystals & Developmental cysts & 39 & Frequent & No \\
\hline \multirow{2}{*}{8.} & Mucous cells & Developmental cysts & 42 & Rarely & $+/-$ \\
\hline & Mucous cells & Nonodontogenic cysts & 54 & Rarely & No \\
\hline \multirow{2}{*}{9.} & Ciliated cells & Developmental cysts & 37 & Rarely & \\
\hline & Ciliated cells & Nonodontogenic cysts & 41 & Rarely & \\
\hline \multirow[t]{2}{*}{10.} & Dystrophic calcification & $\begin{array}{l}\text { Inflammatory cysts and } \\
\text { odontogenic tumors }\end{array}$ & 49 & Frequent & No \\
\hline & Dystrophic calcification & Odontogenic cysts & 47 & Frequent & No \\
\hline \multirow{2}{*}{11.} & Rushton intraepithelial hyaline bodies & $\begin{array}{l}\text { Inflammatory odontogenic } \\
\text { cysts }\end{array}$ & 48 & Rarely & $+/-$ \\
\hline & Rushton hyaline bodies & $\begin{array}{l}\text { Developmental odontogenic } \\
\text { cysts }\end{array}$ & 35 & Rarely & No \\
\hline 12. & $\begin{array}{l}\text { Connective hyaline bodies' inflammatory } \\
\text { reaction }\end{array}$ & Follicular cysts & 38 & $\begin{array}{c}\text { Relatively } \\
\text { often }\end{array}$ & No \\
\hline 13. & $\begin{array}{l}\text { Fibro-myxomatous degeneration of the } \\
\text { wall }\end{array}$ & All inflammatory cysts & 45 & $\begin{array}{l}\text { Relatively } \\
\text { often }\end{array}$ & $\begin{array}{c}\text { +/- (in connection } \\
\text { with odontogenic } \\
\text { epithelial polytopic } \\
\text { hotspots) }\end{array}$ \\
\hline 14. & Plasma cells with Russell bodies & All inflamed cysts & 45 & Frequent & + \\
\hline 15. & Polycystic invaginations & Lateral periodontal cysts & 45 & Frequent & + \\
\hline 16. & Thickening of the epithelium & Lateral periodontal cysts & 45 & Inconstant & + \\
\hline 17. & Deletion of the epithelium crests & Odontogenic keratocyst & 38 & Frequent & + \\
\hline
\end{tabular}

The epithelium that is platted from the support connective tissue is observed at the odontogenous keratocysts. This finding is not a feature of other types of maxillary cysts. The three cases of odontogenic recurrent keratocysts showed not constant this separation of the lining epithelium from the subjacent connective tissue (Figure 1), this observation may explain the recurrence of these cysts (Figure 2, A-C).

The myxomatous modification on the cyst wall indicates dysfunctional local tissue, which may indicate a recurrence possibility (Figure 3 ). The presence of metaplasia mucous cells in ameloblastoma and their comparatively regular occurrence in odontogenic cysts shows the odontogenic epithelium's capacity for differentiation (Figure 4).

The most important predictor of postoperative recurrence risk is active odontogenic epithelial rests in the cyst wall (Figure 5). In two cases, we discovered cyst lumen-lining epithelium with ameloblastoma aspect and basaloid type, which raises the possibility of recurrence or neoplasia transformation (ameloblastoma, the carcinoma with squamous cells, the central mucoepidermoid carcinoma) (Figure 6). Carefully and using objects of increasing the image, we identified in the cyst wall active or inactive small epithelial odontogenic islands with cells in small groups (2-4-6-8 cells), with small central nuclei, sometimes arranged in short cords or in rosettes in a semi-ordered fibrous connective tissue, of ligamental type.

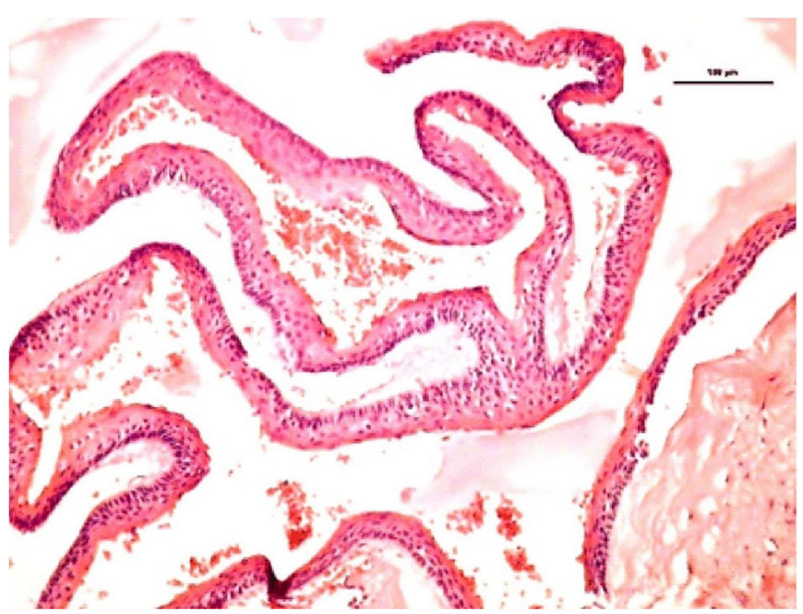

Figure 1 - The wall of an odontogenic keratocyst, with detachment on extended areas of the odontogenic epithelium from the connective tissue (HE staining, $\times 100$ ). 

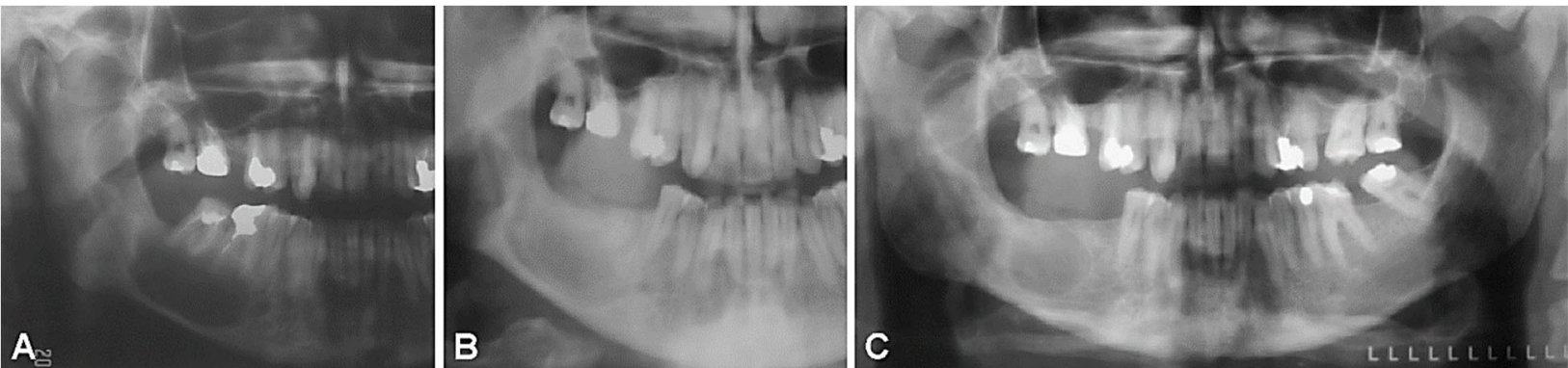

Figure 2 - Radiography of an odontogenic mandibular recurrent keratocyst: (A) preoperative aspect; (B) Six months postoperative; (C) Fourteen months postoperative.

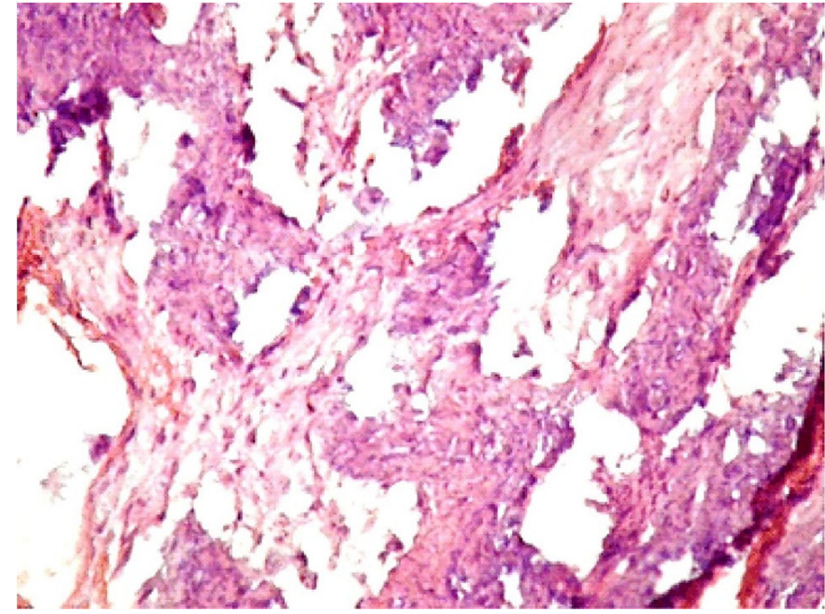

Figure 3 - Cementoid-like material, here and there with osteoid aspect with pseudotrabecular architecture without formation of the spongious bone areolas, formed at the periphery of a giant cyst of mandibular bone (HE staining, $\times 100)$.

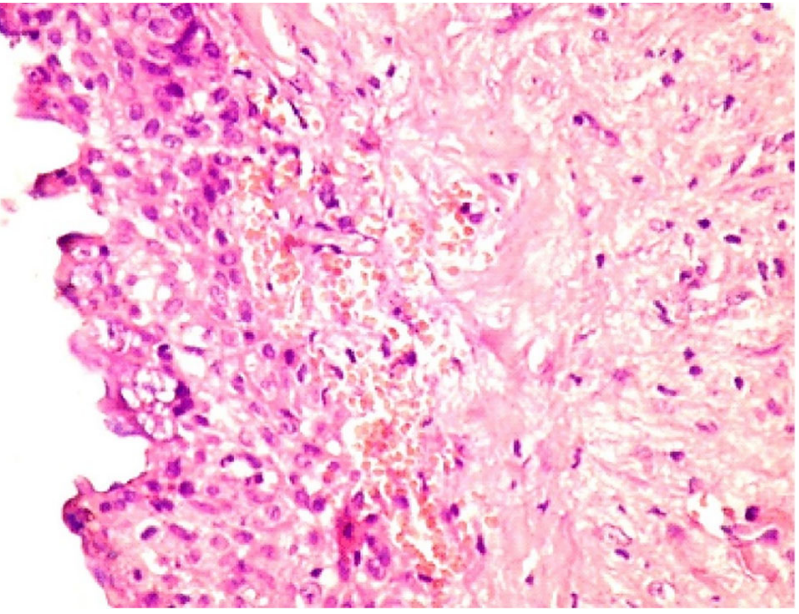

Figure 4 - Stratified odontogenous lining epithelium of the lumen of a dentigerous cyst, presenting cellular differentiation with mucous secretions and cilia (HE staining, $\times 200$ ).

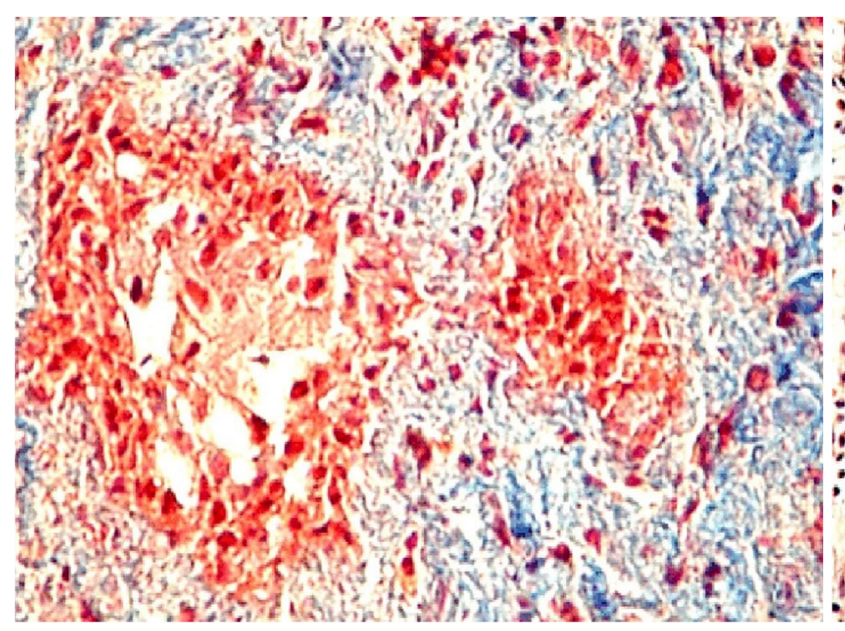

Figure 5 -Active odontogenic epithelium in the wall of a dentigerous cyst (Masson's trichrome staining, $\times 200$ ).

In the inflammatory process, the endothelial cells activated by local proinflammatory factors (monocytes, macrophages), cytokines, initiates reactive angiogenesis identified in the inflammatory stage of different cystic subtypes in our study (Figures 7 and 8). The infarction of vascular wall is a source of intracystic hemorrhage.

The recent cystic lesions present in the wall inflammatory infiltrate predominantly with polymorpho-

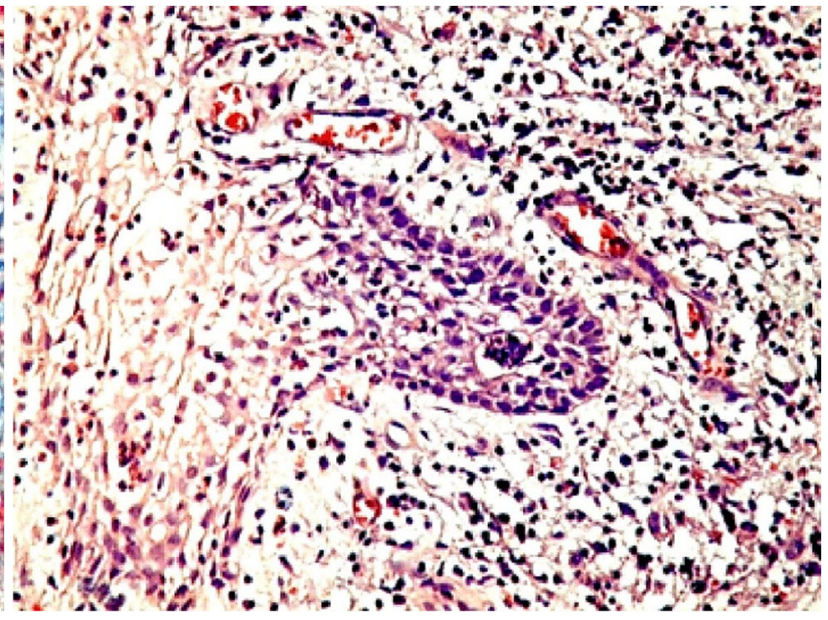

Figure 6 - Epithelial odontogenic island with ameloblastomatous transformation, reversal of the cellular polarity, supranuclear vacuolization, perilesional angiogenesis, polymorphic inflammatory infiltrate (HE staining, $\times 100$ ).

nuclear leukocytes in areas with active hyperemia. In the depth of the wall, inflammatory infiltrate is predominantly mononuclear, characterized by an abundance of plasma cells. The cystic wall presents various grades of fibrosis and hyalinization with bone tissue in peripheral areas.

The cytological aspects were used to determine the cellularity of cystic lesions, to determine the subtype of 
the lesion and the activity score of odontogenic epithelia which indicated the lesion's evolutive prognostic possibilities. Cellular discohesivity by acantholysis, ulceration of the cyst walls, intracystic hemorrhage, the suppuration, inflammatory necrosis, the microcalcifications, the presence of foamy macrophages of resorption indicates a high level of cellular activation, implying that the lesion is unstable (Figures 9 and 10).

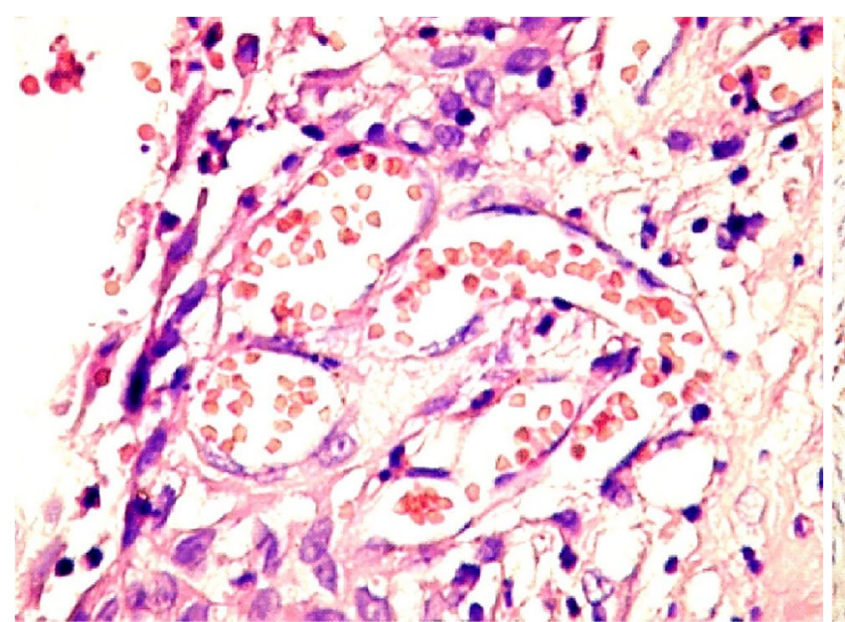

Figure 7 - Appearance of vascular pseudoinvasion in the lining epithelium of a dentigerous cyst, vessel ruptures at the surface of the epithelium, source of intracystic hemorrhage (HE staining, ×200).

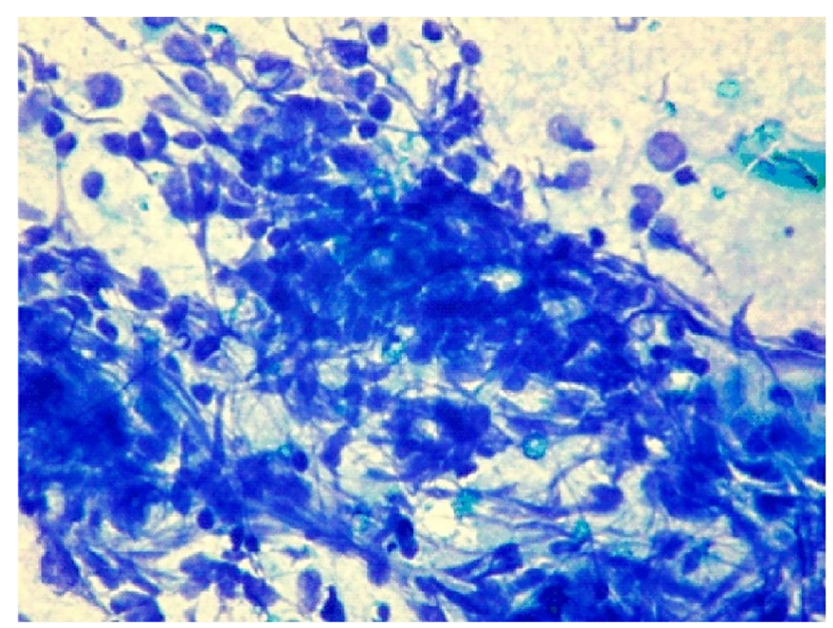

Figure 9 - Radicular inflammatory cyst in phase formation with high cellularity, mixed cellular arrangement, slight nuclear alteration, inflammatory diathesis; cytological smear obtained after a fine-needle aspiration punction (APT-Drăgan staining, ×400).

The appearance of cholesterol crystals in dentigerous cysts indicates an aggressive evolutionary potential. In fact, cholesterol crystals are an indicator of periapical disease, their accumulation being consecutive to an inefficient endodontic therapy.

In our study, we had selected, since the collecting phase, different types of smears - sampling error. To reduce misinterpretation and screening errors, and we also used intraoperative imprint cytology. False negative results may appear in the case of hypocellular smears due to a poor technique FNA or intraoperative imprint cytology or in the case of intense hemorrhagic lesions. Table 2 summarizes the results of cytodiagnosis.

The diagnostic value of TEM was confirmed by a positive diagnosis of HP subtype of cystic lesions. Thus, by the morphological methods of cellular structure identification, TEM, due to its superior resolution,

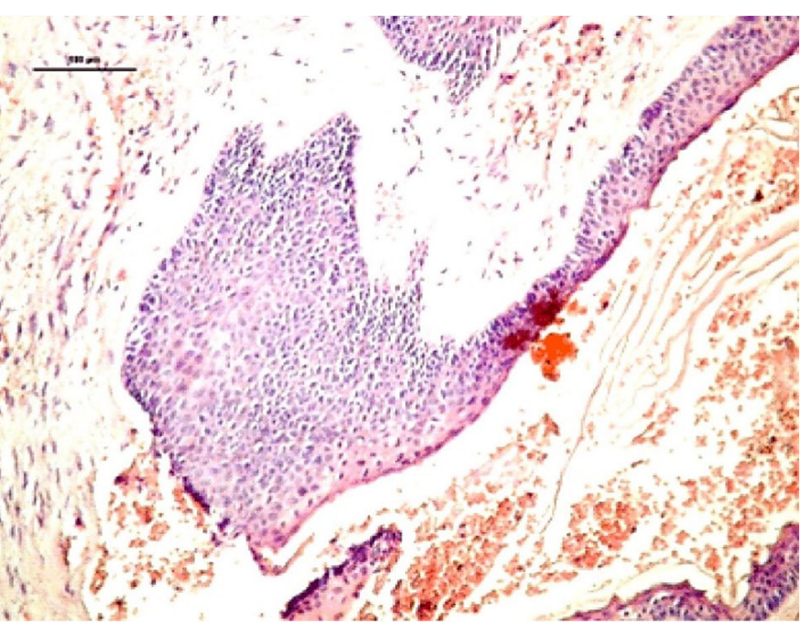

Figure 8 - Odontogenic keratocyst in histopathological differential diagnosis by highlighting epithelial thickening in plaques, polycystic lesion (HE staining, $\times 100)$.

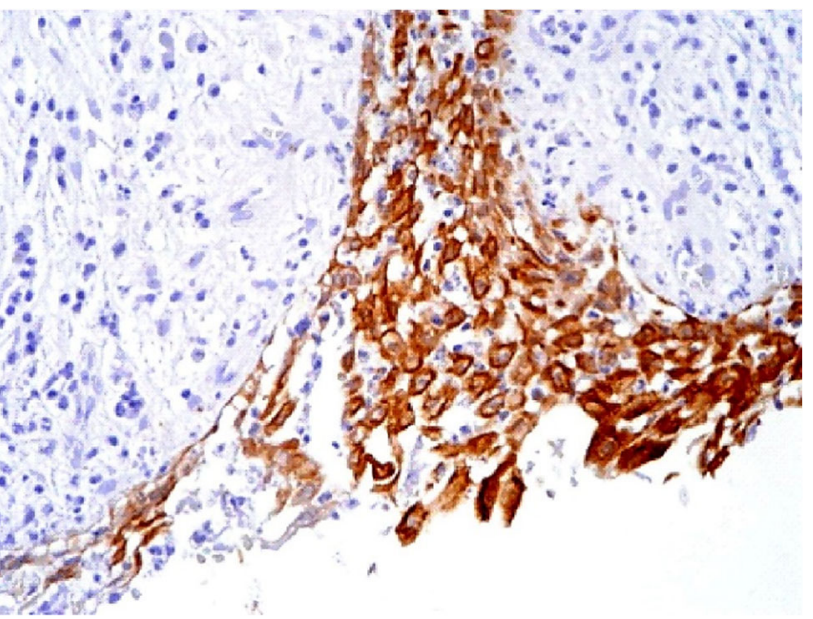

Figure 10 - Acantholytic epithelium with marked cell exfoliation in the cystic lumen (Immunostaining with anti-AE1/AE3 cytokeratin antibody, $\times 200)$.

allowed us to localize to an ultrastructural level the following substrates (Table 3).

We frequently found in the cytoplasm of fibroblasts intracellular tropocollagen, some of them included in electron clear vacuoles with or without keeping the periodicity of the characteristic. These ones represent temporal sequences of intracellular collagen degradation (Figures 11 and 12).

Odontogenic cells are inactive (Figures 13 and 14), without aspects of division, corresponding immunohistochemically to a Ki67 index of $0 \%$ in the walls of radicular and dentigerous odontogenic cysts, suggestive for the phase of morphological stabilization of the cyst that became symptomatic. The absence of nervous filets or their lysis in the thickness of the cystic wall suggests a painless, latent increasing of the cyst, even in the presence of activated inflammatory cells. 
Table 2 - Results of cytodiagnosis

\begin{tabular}{|c|c|c|c|c|c|c|c|c|c|c|c|c|c|}
\hline \multirow{2}{*}{$\begin{array}{l}\text { Cyto- } \\
\text { diagnosis } \\
\text { guide }\end{array}$} & \multirow{2}{*}{ Histodiagnosis } & \multicolumn{3}{|c|}{ Cellularity } & \multicolumn{3}{|c|}{$\begin{array}{c}\text { Dimension groups } \\
\text { epithelial cells }\end{array}$} & \multicolumn{2}{|c|}{$\begin{array}{c}\text { Cellular } \\
\text { arrangement }\end{array}$} & \multicolumn{3}{|c|}{$\begin{array}{l}\text { No. of isolated } \\
\text { epithelial cells }\end{array}$} & \multirow{2}{*}{$\begin{array}{l}\text { No. of } \\
\text { cases }\end{array}$} \\
\hline & & $\begin{array}{c}\text { grade } \\
I\end{array}$ & $\begin{array}{c}\text { grade } \\
\text { II }\end{array}$ & $\begin{array}{c}\text { grade } \\
\text { III }\end{array}$ & small & big & mixed & simple & complex & $\begin{array}{c}\text { grade } \\
I\end{array}$ & $\begin{array}{c}\text { grade } \\
\text { II }\end{array}$ & $\begin{array}{c}\text { grade } \\
\text { III }\end{array}$ & \\
\hline $\begin{array}{l}\text { Benign } \\
\text { smear }\end{array}$ & $\begin{array}{l}\text { Inactive odontogenic } \\
\text { cyst }\end{array}$ & 1 & 0 & 0 & 1 & 0 & 0 & 1 & 0 & 0 & 1 & 0 & 18 \\
\hline $\begin{array}{l}\text { Benign } \\
\text { smear }\end{array}$ & $\begin{array}{l}\text { Odontogenic cyst with } \\
\text { marked inflammation }\end{array}$ & 0 & 0 & 1 & 0 & 1 & 1 & 0 & 1 & 0 & 1 & 0 & 27 \\
\hline $\begin{array}{l}\text { Benign } \\
\text { smear }\end{array}$ & $\begin{array}{l}\text { Active odontogenic } \\
\text { cyst with ameloblastic } \\
\text { potential }\end{array}$ & 0 & 1 & 1 & 0 & 1 & 1 & 1 & 0 & 1 & 1 & 0 & 30 \\
\hline $\begin{array}{l}\text { Benign } \\
\text { smear }\end{array}$ & $\begin{array}{l}\text { Inactive odontogenic } \\
\text { cyst in remission }\end{array}$ & 1 & 0 & 0 & 1 & 0 & 1 & 1 & 0 & 1 & 0 & 0 & 15 \\
\hline $\begin{array}{l}\text { Benign } \\
\text { smear }\end{array}$ & Nonodontogenic cyst & 0 & 1 & 0 & 0 & 0 & 1 & 0 & 1 & 1 & 0 & 0 & 6 \\
\hline $\begin{array}{l}\text { Benign } \\
\text { smear }\end{array}$ & Pseudocysts & 0 & 1 & 0 & 0 & 0 & 0 & 0 & 1 & 0 & 0 & 0 & 3 \\
\hline $\begin{array}{l}\text { Benign } \\
\text { smear }\end{array}$ & $\begin{array}{l}\text { Mesenchymal benign } \\
\text { tumors }\end{array}$ & 1 & 1 & 0 & 0 & 0 & 0 & 1 & 0 & 0 & 0 & 0 & 15 \\
\hline $\begin{array}{c}\text { Malignant } \\
\text { smear }\end{array}$ & $\begin{array}{l}\text { Neoplasms and other } \\
\text { maxillary bone lesions }\end{array}$ & 1 & 1 & 1 & 0 & 0 & 1 & 1 & 1 & 0 & 1 & 1 & 6 \\
\hline
\end{tabular}

Table 3 - Aspects of cells commonly found in TEM in the walls of maxillary odontogenic cysts

\begin{tabular}{llll}
\hline \multicolumn{1}{c}{$\begin{array}{c}\text { Morphological } \\
\text { substrate }\end{array}$} & \multicolumn{1}{c}{ Fibroblast } & Benign odontogenic epithelial cell & \multicolumn{1}{c}{ Macrophage } \\
\hline Nucleus & $\begin{array}{l}\text { Non-crenellated } \\
\text { With numerous nuclear pores } \\
\text { Prominent nucleolus }\end{array}$ & Indented & $\begin{array}{l}\text { Non-crenellated or irregular } \\
\text { consequence of morphofunctional } \\
\text { differentiation - cell invaginations } \\
\text { Scintillation }\end{array}$ \\
\hline RER cisternae & $\begin{array}{l}\text { Numerous } \\
\text { Parallel }\end{array}$ & Numerous & $\begin{array}{l}\text { Depending on the morphofunctional } \\
\text { differentiation }\end{array}$ \\
\hline Golgi sacs & $\begin{array}{l}\text { Dilated } \\
\text { Numerous }\end{array}$ & Dilated \\
Numerous & Numerous \\
\hline Microtubules & Non-oriented & Non-oriented & $\begin{array}{l}\text { Numerous depending on the } \\
\text { morphofunctional differentiation }\end{array}$ \\
\hline Intracellular fibrillar & $\begin{array}{l}\text { Present "intracellular collagen } \\
\text { collagen }\end{array}$ & Present & Present endocytic material \\
\hline Cellular invaginations & & & Present \\
\hline $\begin{array}{l}\text { Solitary cilium toward } \\
\text { matrix }\end{array}$ & Sometimes present & Absent & Inconstant \\
\hline Intercellular contacts & Gap & $\begin{array}{l}\text { Gap } \\
\text { Desmosomes } \\
\text { Zonula adherens and zonula occludens }\end{array}$ & \\
\hline Inclusions of glycogen & Present & $\begin{array}{l}\text { Poorly represented in the cells of the } \\
\text { active proliferative group }\end{array}$ & $\begin{array}{l}\text { Present with other inclusions } \\
\text { (lipids, hemosiderinic pigment) }\end{array}$ \\
\hline Basal lamina & Film stress & Fragmented & Absent \\
\hline Lysosomes & Numerous & Inconstant diffusely scattered & Numerous autophagosomes \\
\hline
\end{tabular}

RER: Rough endoplasmic reticulum; TEM: Transmission electron microscopy.

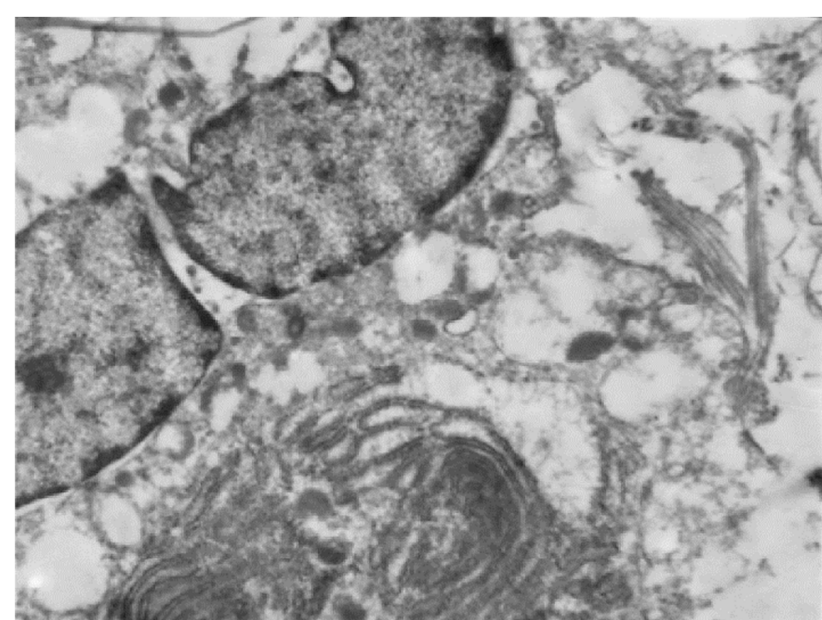

Figure 11 - Fibroblast indented nucleus, apparently bilobed in section, euchromatic, active and Golgi area, secretory vesicles and endocytosed fibrillar material (TEM, ×40 000).

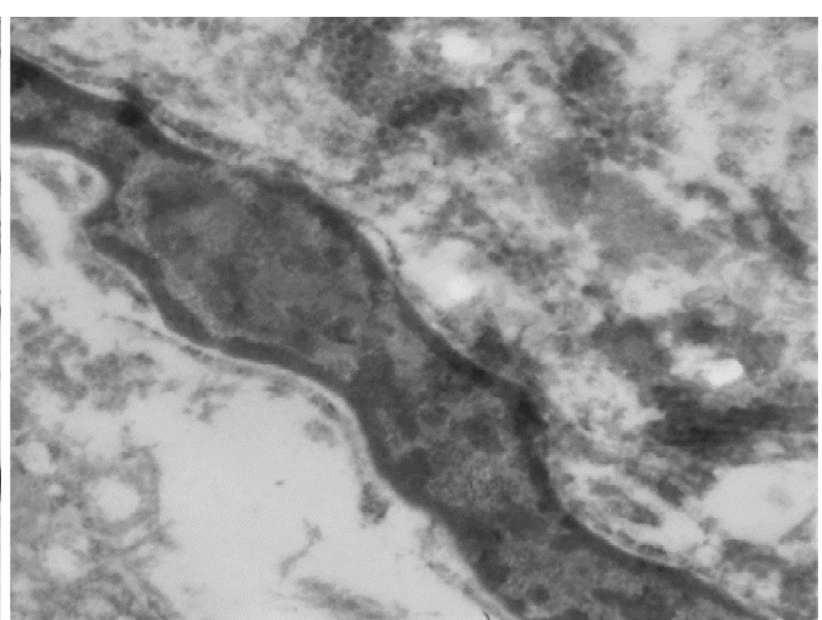

Figure 12 - Appearance of a fibroblast surrounded by collinear "stress" fibers, interconnected with extracellular filaments via fibronexus in the conjunctival matrix of an inflammatory odontogenic cyst (TEM, $\times 40$ 000). 


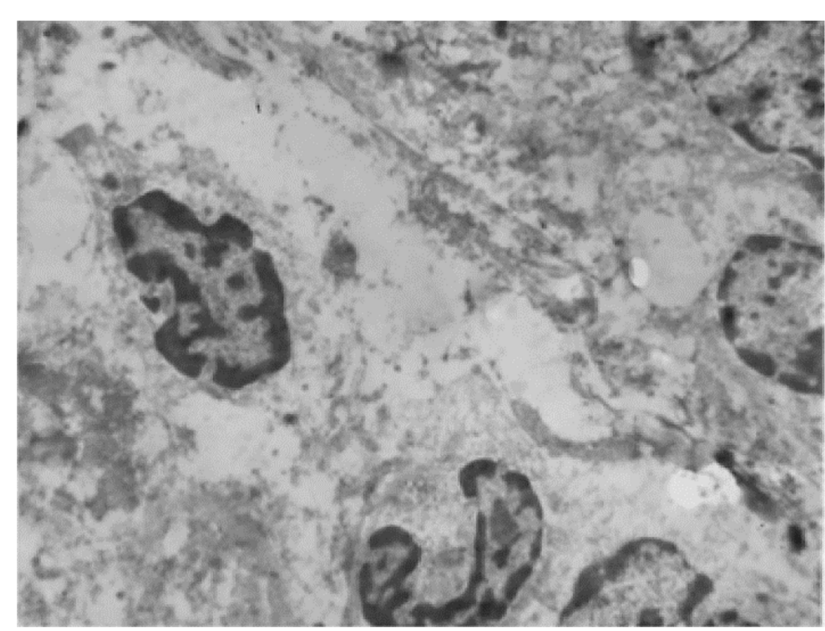

Figure 13 - Discontinuous group of odontogenic epithelial cells, discontinuities of the basal membrane and of the intercellular contacts are noticed (TEM, $\times 40000)$

\section{ㅁ Discussions}

The recognition and selection of embryonary remnants from odontogenesis is decisive for the HP diagnosis of maxillary cysts, allowing the clinician to monitor the treatment or to elaborate the evolutive prognosis perspectives of odontogenic and tumor cystic lesions [7-10]. The integrative results of our study identified the following parameters considered risks of recurrence: epithelial clear cell nests and islands, glycogen well represented and extended in the connective tissue; multilocular type of cyst; compartmentalization of the cavity cyst; multipolar origin of cystic lesions; mucous, apocrine, ciliated metaplasia of the epithelium (for mucoepidermoid carcinoma, ameloblastoma); epithelium parakeratinization (odontogenic keratocyst); basal buds; solid epithelial proliferations.

Some etiological factors seem to continue their cystic formative action even after the removal of the initial lesion $[2,4,8,11]$. After complete tooth development, epithelial rests from odontogenesis remain inactive for an undetermined period. As soon as they are stimulated by factors still incompletely elucidated, these remnants of tissue proliferate and initiate the formation of epithelial lining epithelium of cysts.

Medical literature [12] brings extradata in IHC studies on tissue differentiation in the cystic wall and anticipates the evolution of cystic lesion expansion, by identifying some matrix molecules (fibronectin, tenascin, syndecan, etc.) and some growth factors (neurotrophins, endothelial growth and proliferation factors). The presence of maxillary cysts to twins, brothers, or relatives of different degrees in connection with certain diseases proven to have been induced by genomic perturbations $[6,12]$ suggests the specificity of lesioned substrate in the cystic wall, due to modifications of protein synthesis, of sugar-protein-lipid metabolism and of particularities of inflammatory effect in the generation and maintenance of cystic lesions. That is how we explain in our study the identification of the same type of maxillary cyst (radicular cyst, $n=2$ ) with identical mandibular topography at brothers of similar ages. Epithelial-mesenchymal transformation, on the other hand, is a natural phase that occurs during multicellular organisms' embryonic morphogenesis during which

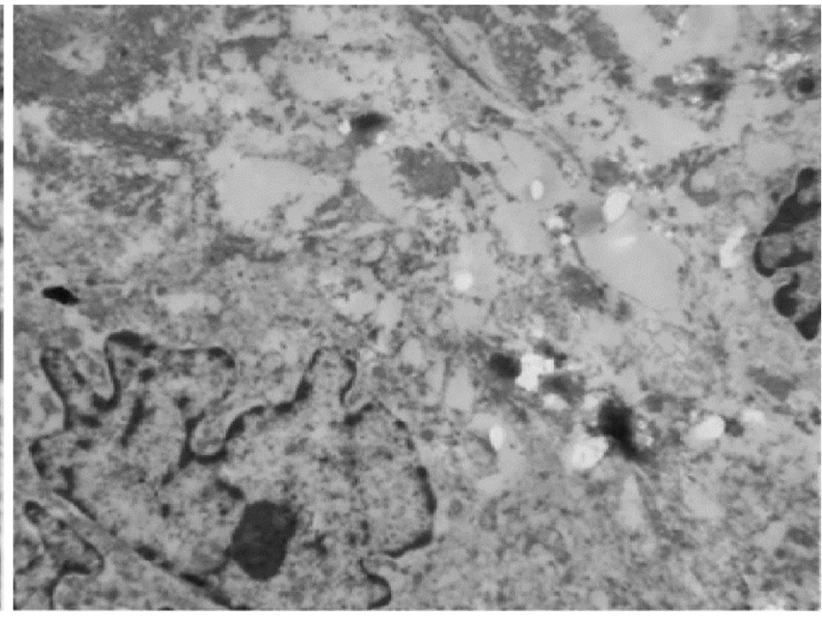

Figure 14 - Nucleus of odontogenic epithelial cell with multiple indentations, with expressed nucleolus, the cell is interconnected in a small cell group delimited by a discontinuous basement membrane (TEM, $\times 40$ 000).

embryonic mesenchymal cells develop and become mobile, losing their cellular polarity. After migrating in the locus intended for differentiation, they lose their mobility. Contrary to the common embryonic process, in some affections like neoplastic proliferations or growths of cyst-type, the epithelial-mesenchymal transition cells produce autocrine circuits of growth signals, evades apoptosis, and induce angiogenesis to ensure a surplus of tissue vascularity [13]. It is the explanation for the rapid development of cystic lesions in the context of angiogenesis induced by the inflammatory process or other processes still unexplained in this study.

These tissue modifications are interpreted in the medical literature $[13,14]$ in connection with perturbations of the expression of certain growth factors, cellular adhesion (its losing or amplification) of adherents and certain subcellular structures that maintain cellular polarity. Numerous studies $[1,2,4]$ show that epithelial cells of periodontal ligament interact with proteins of cellular matrix, through different adhesive molecules (fibronectin, tenascin). Other studies draw attention to endotoxins in the necrotic pulp tissue, which can induce stimulation and proliferation of Malassez epithelial cells, which produces the formation of radicular cysts [1, 4].

Epithelial rests can migrate, proliferate, and differentiate into the constitution of a cystic lesion wall by participating the cellular matrix. However, the mechanisms of lesional development and progression are controversial, the data of cytogenetic and molecular biology are to clear the stages of formation and differentiation of maxillary cystic walls $[13,14]$.

Collagen intracellular degradation is possible after the glycoproteins such as fibronectin and proteoglycans are cleaved from the fiber surface. Their removal is performed using stromelysin [matrix metalloproteinase-3 (MMP)-3]. Intracellular degradation is made with specific enzymes - collagenase (MMP-1). This cleaves the triple helix side of collagen molecules, causing the fiber fragmentation, with MMP-4. Next, the gelatinase MMP-2 and MMP-5 acts. The more accelerated is the degradative matrix activity by proliferation or growth inflammatory factors which intensify cellular activity, the bigger is the instability of the cystic wall structure $[1,10]$. 
Recent HP and cytogenetical studies cannot certainly precise which epithelial rests are more susceptible to risk of proliferation, migration and thus constitution of the cyst lining, whenever are studied either Malassez rests from which derive periapical (radicular) cysts or the reduced epithelium of enamel, which is at the origin of dentigerous cysts and cyst eruption, or rests of dental lamina (Serres rests) that are at the origin of odontogenic keratocysts, lateral periodontal, gingiva to the adult or of dental lamina to the newborn, of glandular odontogenic cyst [14].

\section{Conclusions}

Various classifications of cystic lesions of the maxillary bone point to the necessity of better knowledge of the origin and differentiation of tissue components of cysts structure. To sustain with certainty, the diagnosis of odontogenic cyst is needed clinical and radiological information convergent to the HP one. The HP aspects can be similar even to cystic lesions, which are differently classified. We can interpret that the expansion of the cystic wall depends on the imprinted tensioactive forces: the accumulation of necrotic cellular material in the lumen; proliferative activity of odontogenic epithelial rests and connective morphogenesis of the wall in which fibroblasts occupy the central place. These cells seem to have a high polarity of the migration activity, which transforms them by modulation into myofibroblasts. Knowing the morphological substrates involved in the formation and growth of cystic walls, we could speculate about the introduction of innovative therapy, complementary to surgical enucleation of inflammatory and developmental odontogenic maxillary cysts.

\section{Institutional Review Board statement}

The study was conducted according to the Guidelines of the Declaration of Helsinki and approved by the Institutional Review Board of Emergency Clinical Municipal Hospital, Timişoara, Romania (Approval No. E-5947/ 29.03.2019).

\section{Informed consent statement}

Written informed consent has been obtained from the patients to publish this paper.

\section{Data availability statement}

The data presented in this study are available on request from the corresponding author. The data are not publicly available due to patient confidentiality.

\section{Conflict of interests}

The authors declare that they have no conflict of interests.

\section{References}

[1] Arsenic R, Kurrer MO. Differentiated dysplasia is a frequent precursor or associated lesion in invasive squamous cell carcinoma of the oral cavity and pharynx. Virchows Arch, 2013, 462(6):609-617. https://doi.org/10.1007/s00428-0131412-6 PMID: 23588556

[2] Luan $X$, Ito $Y$, Diekwisch TGH. Evolution and development of Hertwig's epithelial root sheath. Dev Dyn, 2006, 235(5):11671180. https://doi.org/10.1002/dvdy.20674 PMID: 16450392 PMCID: PMC2734338

[3] Brøndum N, Jensen VJ. Recurrence of keratocysts and decompression treatment. A long-term follow-up of forty-four cases. Oral Surg Oral Med Oral Pathol, 1991, 72(3):265269. https://doi.org/10.1016/0030-4220(91)90211-t PMID: 1717918

[4] Cardesa A, Slootweg PJ, Gale N, Franchi A (eds). Pathology of the head and neck. $2^{\text {nd }}$ edition, Springer-Verlag, BerlinHeidelberg, Germany, 2016. https://link.springer.com/book/ 10.1007\%2F978-3-662-49672-5

[5] Cawson RA, Odell EW, Porter SR. Cawson's essentials of ora pathology and medicine. $7^{\text {th }}$ edition, Churchill Livingstone, Elsevier, London, UK, 2002. https://archive.org/details/cawsons essential00caws/mode/2up

[6] Frable WJ, Frable MA. Thin-needle aspiration biopsy in the diagnosis of head and neck tumors. Laryngoscope, 1974, 84(7):1069-1077. https://doi.org/10.1288/00005537-197407 000-00001 PMID: 4407746

[7] Kierszenbaum AL, Tres LL. Histology and cell biology: an introduction to pathology. $5^{\text {th }}$ edition, Elsevier, Philadelphia, USA, 2019, 517-520. https://www.elsevier.com/books/histo logy-and-cell-biology-an-introduction-to-pathology/kierszen baum/978-0-323-67321-1

[8] Parums DV (ed). Essential clinical pathology. $1^{\text {st }}$ edition, Wiley-Blackwell Science, Oxford, UK, 1996.

[9] Sciubba JJ, Fantasia JE, Kahn LB. Tumors and cysts of the jaw. In: ${ }^{* \star *}$. Atlas of tumor pathology. $1^{\text {st }}$ edition, Armed Forces Institute of Pathology (AFIP), American Registry of Pathology, Washington DC, USA, 2001.

[10] Seltmann K, Fritsch AW, Käs JA, Magin TM. Keratins significantly contributes to cell stiffness and impact invasive behavior. Proc Natl Acad Sci U S A, 2013, 110(46):1850718512. https://doi.org/10.1073/pnas.1310493110 PMID: 24167274 PMCID: PMC3832002

[11] Singh S, Garg N, Gupta S, Marwah N, Kalra R, Singh V, Sen R. Fine needle aspiration cytology in lesions of oral and maxillofacial region: diagnostic pitfalls. J Cytol, 2011, 28(3):9397. https://doi.org/10.4103/0970-9371.83461 PMID: 21897540 PMCID: PMC3159298

[12] Ruocco V, Pinto F. Cytodiagnosis for oral disorders. In: Lotti TM, Parish LC, Rogers RS (eds). Oral diseases. $1^{\text {st }}$ edition, SpringerVerlag, Berlin-Heidelberg, Germany, 1999, 23-29. https://doi. org/10.1007/978-3-642-59821-0_4

[13] Wang M, Zhao J, Zhang L, Wei F, Lian Y, Wu Y, Gong Z, Zhang S, Zhou J, Cao K, Li X, Xiong W, Li G, Zeng Z, Guo C. Role of tumor microenvironment in tumorigenesis. J Cancer, 2017, 8(5):761-773. https://doi.org/10.7150/jca.17648 PMID: 28382138 PMCID: PMC5381164

[14] Weiss SW, Goldblum RJ, Folpe AL (eds). Enzinger and Weiss's soft tissue tumors. $6^{\text {th }}$ edition, Elsevier-Saunders, Philadelphia, USA, 2013, 12-167. https://www.elsevier.com/ books/enzinger-and-weisss-soft-tissue-tumors/goldblum/978 $-0-323-08834-3$

\section{Corresponding authors}

Ciprian loan Roi, Associate Professor, MD, DMD, PhD, Department of Anesthesiology and Oral Surgery, Multidisciplinary Center for Research, Evaluation, Diagnosis and Therapies in Oral Medicine, Faculty of Dental Medicine, Victor Babeş University of Medicine and Pharmacy, 2 Eftimie Murgu Square, 300041 Timişoara, Romania; Phone +40748-245 993, e-mail: ciprian.roi@umft.ro

Stela lurciuc, Lecturer, MD, PhD, Discipline of Ambulatory Internal Medicine, Cardiovascular Prevention and Rehabilitation, Department of Cardiology, Faculty of Medicine, Victor Babeş University of Medicine and Pharmacy, 2 Eftimie Murgu Square, 300041 Timişoara, Romania; Phone +40726-307 293, e-mail: stela_iurciuc@yahoo.com 